CrossMark \&click for updates

Cite this: Phys. Chem. Chem. Phys., 2016, 18, 8980

Received 17th January 2016 Accepted 24th February 2016

DOI: $10.1039 / c 6 c p 00365 f$

www.rsc.org/pccp

\section{Aromaticity of the doubly charged [8]circulenes $\dagger$}

\author{
Gleb V. Baryshnikov, ${ }^{\star a b}$ Rashid R. Valiev, ${ }^{\text {cd }}$ Nataliya N. Karaush, ${ }^{b}$ Dage Sundholm ${ }^{e}$ \\ and Boris F. Minaev ${ }^{\text {bf }}$
}

\begin{abstract}
Magnetically induced current densities and current pathways have been calculated for a series of fully annelated dicationic and dianionic tetraphenylenes, which are also named [8]circulenes. The gauge including magnetically induced current (GIMIC) method has been employed for calculating the current density susceptibilities. The aromatic character and current pathways are deduced from the calculated current density susceptibilities showing that the neutral [8]circulenes have two concentric pathways with aromatic and antiaromatic character, respectively. The inner octatetraene core (the hub) is found to sustain a paratropic (antiaromatic) ring current, whereas the ring current along the outer part of the macrocycle (the rim) is diatropic (aromatic). The neutral [8]circulenes can be considered nonaromatic, because the sum of the ring-current strengths of the hub and the rim almost vanishes. The aromatic character of the doubly charged [8]circulenes is completely different: the dianionic [8]circulenes and the $\mathrm{OC}-, \mathrm{CH}_{-}, \mathrm{CH}_{2^{-}}, \mathrm{SiH}-, \mathrm{GeH}_{-}, \mathrm{SiH}_{2-}$, and $\mathrm{GeH}_{2}$-containing dicationic species sustain net diatropic ring currents i.e., they are aromatic, whereas the $\mathrm{O}_{-}, \mathrm{S}-, \mathrm{Se}-, \mathrm{NH}-, \mathrm{PH}-$ and $\mathrm{AsH}$-containing dicationic [8]circulenes are strongly antiaromatic. The present study also shows that GIMIC calculations on the [8]circulenes provide more accurate information about the aromatic character than that obtained using local indices such as nuclear-independent chemical shifts (NICSs) and ${ }^{1} \mathrm{H}$ NMR chemical shifts.
\end{abstract}

\section{Introduction}

Aromaticity is one of the most important and controversial concepts in chemistry characterizing the physical properties and chemical reactivity of chemical compounds. ${ }^{1,2}$ Aromaticity is a complicated property due to its multidimensional character i.e., different means to assess the degree of aromaticity might lead to various results. In addition, aromaticity cannot be obtained directly from experiment, even though it is commonly used for understanding chemical properties. ${ }^{2-5}$ Many different approaches have been proposed for assessing and quantifying the degree of aromaticity of entire molecules or of parts

\footnotetext{
${ }^{a}$ Division of Theoretical Chemistry and Biology, School of Biotechnology, KTH Royal Institute of Technology, 10691 Stockholm, Sweden. E-mail: glebchem@rambler.ru; Fax: +38 0472 354463; Tel: +38 0472376576

${ }^{b}$ Department of Organic Chemistry, Bohdan Khmelnitsky National University, blvd. Shevchenko 81, 18031, Cherkasy, Ukraine

${ }^{c}$ Tomsk Polytechnic University, 30 Lenin Avenue, 634050, Tomsk, Russia

${ }^{d}$ Tomsk State University, 36 Lenin Avenue, 634050, Tomsk, Russia

${ }^{e}$ Department of Chemistry, University of Helsinki, P.O. Box 55 (A.I. Virtanens plats 1), Helsinki Fin-00014, Finland

${ }^{f}$ Key Laboratory of Engineering Plastics and Beijing National Laboratory for Molecular Science, Institute of Chemistry, Chinese Academy of Science, 100190 Beijing, China

$\dagger$ Electronic supplementary information (ESI) available: Cartesian coordinates and the corresponding total energy of the singlet ground state of the studied [8]circulenes 1-13. See DOI: 10.1039/c6cp00365f
}

of molecules. $^{1,2,6-8}$ The most popular ways to determine the degree of aromaticity are structural, energetic and magnetic criteria. Nucleus-independent chemical shift $(\mathrm{NICS})^{8}$ calculations represent the most widely used magnetic criterion for evaluating aromaticity. NICS values are the magnetic shieldings with an opposite sign calculated in selected points near the molecule under consideration. NICS values are local indicators of the strength of the ring current circling around the studied molecular ring; the NICS provides qualitative information about the aromaticity, antiaromaticity or nonaromaticity of monocyclic systems like benzene, cyclobutadiene, cyclooctatetraene, furan, pyrrole, etc. ${ }^{8}$ However, the NICS approach cannot be employed for assessing the aromatic character of more complicated molecules, ${ }^{9,10}$ which has previously been discussed in a number of studies of the aromatic character of polycyclic aromatic hydrocarbons, ${ }^{11,12}$ porphyrins, ${ }^{13}$ all-metal aromatic compounds ${ }^{14-18}$ and hydrogen-bonded molecular clusters. ${ }^{19}$

A more direct approach to evaluate the aromatic or antiaromatic nature of molecules as a whole is to use the gaugeincluding magnetically induced current (GIMIC) method. ${ }^{20-26}$ The GIMIC approach employs gauge-including atomic orbitals (GIAOs) in explicit calculations of the magnetically induced current density susceptibilities, current strengths and current pathways in molecules providing detailed information about electronic delocalization properties. Some interesting examples of GIMIC applications are current density studies on fullerene 

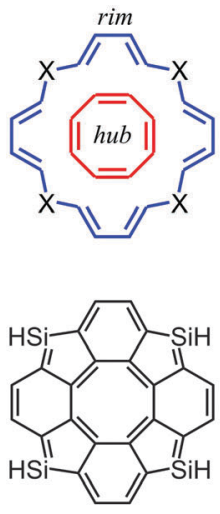

10
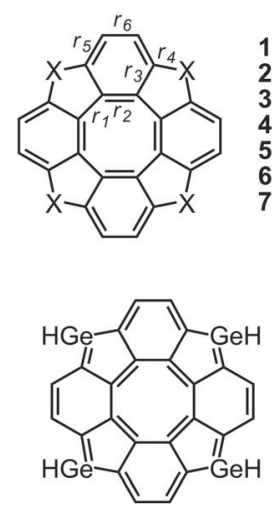

11
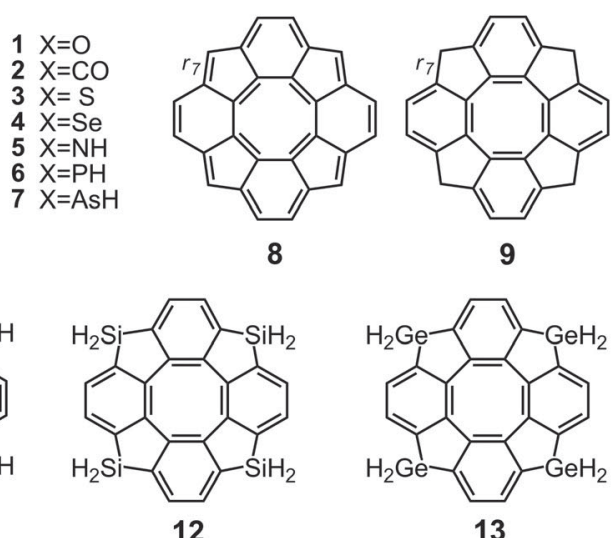

12

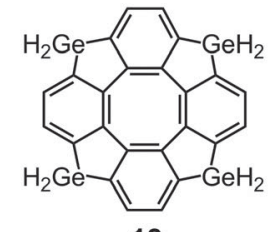

13

Fig. 1 The molecular structures of the [8]circulenes 1-13.

$\mathrm{C}_{60}$ and its multicharged $\mathrm{C}_{60}{ }^{10+}$ ion, ${ }^{27}[n]$ cycloparaphenylenes, ${ }^{28}$ nano-sized hydrocarbons, ${ }^{29}$ etc.

The aromaticity concept has recently been applied to a wide variety of conjugated polyheterocyclic compounds in order to understand their chemical properties. ${ }^{30-34}$ Among them, hetero[8]circulenes possess a prominent place due to their peculiar electronic structure, ${ }^{35-42}$ symmetry ${ }^{40,43,44}$ self-assembling possibilities $^{45-49}$ and specific aromatic properties. ${ }^{50-53}$ Moreover, they also show potential as nanophotonic and microelectronic platforms for the fabrication of organic light-emitting diodes (OLEDs) ${ }^{54-57}$ The aromatic nature of this class of compounds has been extensively studied using the structural, energetic, electronic and magnetic criteria. ${ }^{40-44,51-53}$ Recently, ${ }^{53}$ we reported computational studies of the aromatic properties for a series of neutral ${ }^{58}$ hetero[8]circulenes 1-7 and their hydrocarbon analogues 8 and $\mathbf{9}$ shown in Fig. 1.

In our previous study, we found that the [8]circulenes 1-9 are almost nonaromatic molecules (except compound 8), because the inner paratropic ring current is only slightly larger than the diatropic ring current flowing mainly along the outer part of the molecule leading to a practically vanishing total ring-current strength. ${ }^{53}$ The aromaticity of the novel Si- and Ge-containing [8]circulenes 10-13 (Fig. 1) is investigated for the first time in this work.

In the present work, GIMIC calculations are employed for characterizing the aromaticity of the doubly charged [8]circulenes and the obtained results are compared with the degree of aromaticity deduced from NICS and proton nuclear magnetic resonance ( ${ }^{1} \mathrm{H}$ NMR) calculations.

\section{Computational methods}

The ground-state geometries of the examined species were optimized at the density functional theory (DFT) level by employing the B3LYP ${ }^{59,60}$ functional and the $6-311++\mathrm{G}(\mathrm{d}, \mathrm{p})$ basis set. ${ }^{61}$ The GAUSSIAN 09 package was used. ${ }^{62}$ Hessian calculations indicate that the obtained geometries of the studied species correspond to genuine minima on the potential energy surfaces at the employed level of theory.
NICS indices ${ }^{8,63-66}$ were calculated at the same level of theory by employing gauge-including atomic orbitals (GIAOs) ${ }^{67,68}$ The NICS values were calculated at ghost atoms located at the center of each ring (denoted as NICS(0)) and at a distance of $1 \AA$ above the ring center (NICS(1)). The NICS(1) values were not calculated for the non-planar species. NICS(1) indices are commonly used for better accounting of the magnetic $\pi$-electron effects ${ }^{65,66}$ while NICS(0) indices are considered for evaluating the sum of the $\sigma$ - and $\pi$-electron delocalization effects.

Negative NICS values indicate that the molecule sustains a diatropic ring current, i.e., the ring is aromatic; positive NICS values correspond to paratropic ring currents, i.e., the ring is antiaromatic. ${ }^{69}$ When the NICS value is close to zero, the ring is nonaromatic.

Magnetically induced current density susceptibilities were calculated using the GIMIC method. ${ }^{20-24,70,71}$ Nuclear magnetic resonance (NMR) shielding calculations that are needed for the GIMIC calculations of the current-density susceptibilities and the ring-current susceptibilities, which are also called current densities and ring-current strengths (in $\mathrm{nA} \mathrm{T}^{-1}$ ), were performed using the Turbomole software package. ${ }^{72}$ The calculated ring-current strengths can be used as an aromaticity index. For example, the current strength of the aromatic benzene molecule is $11.8 \mathrm{nA} \mathrm{T}^{-1}$ at the B3LYP/TZVP level as compared with $-19.9 \mathrm{nA} \mathrm{T}^{-1}$ for the antiaromatic cyclobutadiene and $0.2 \mathrm{nA} \mathrm{T}^{-1}$ for the nonaromatic cyclohexane. ${ }^{22}$ The current density plots have been generated using the JMOL package. ${ }^{73}$

The calculations were performed at the PDC supercomputer of the Royal Institute of Technology (Stockholm), at the CSC supercomputer of the Finnish IT Center for Science (Finland), and at the Tomsk State University (SKIF, Russia).

\section{Results and discussion}

\subsection{Molecular structures}

Bond lengths of the optimized structures for the doubly charged [8]circulenes 1-13 and for the novel neutral species 10-13 are given in Table 1 . The studied O-, N-, CO- and $\mathrm{CH}-$ containing neutral [8]circulenes are planar with a strong bond-length 
Table 1 Selected bond lengths (in $\AA$ ) of the singlet ground state of the doubly charged fully annelated tetraphenylenes 1-13 calculated at the B3LYP/6$311++G(d, p)$ level

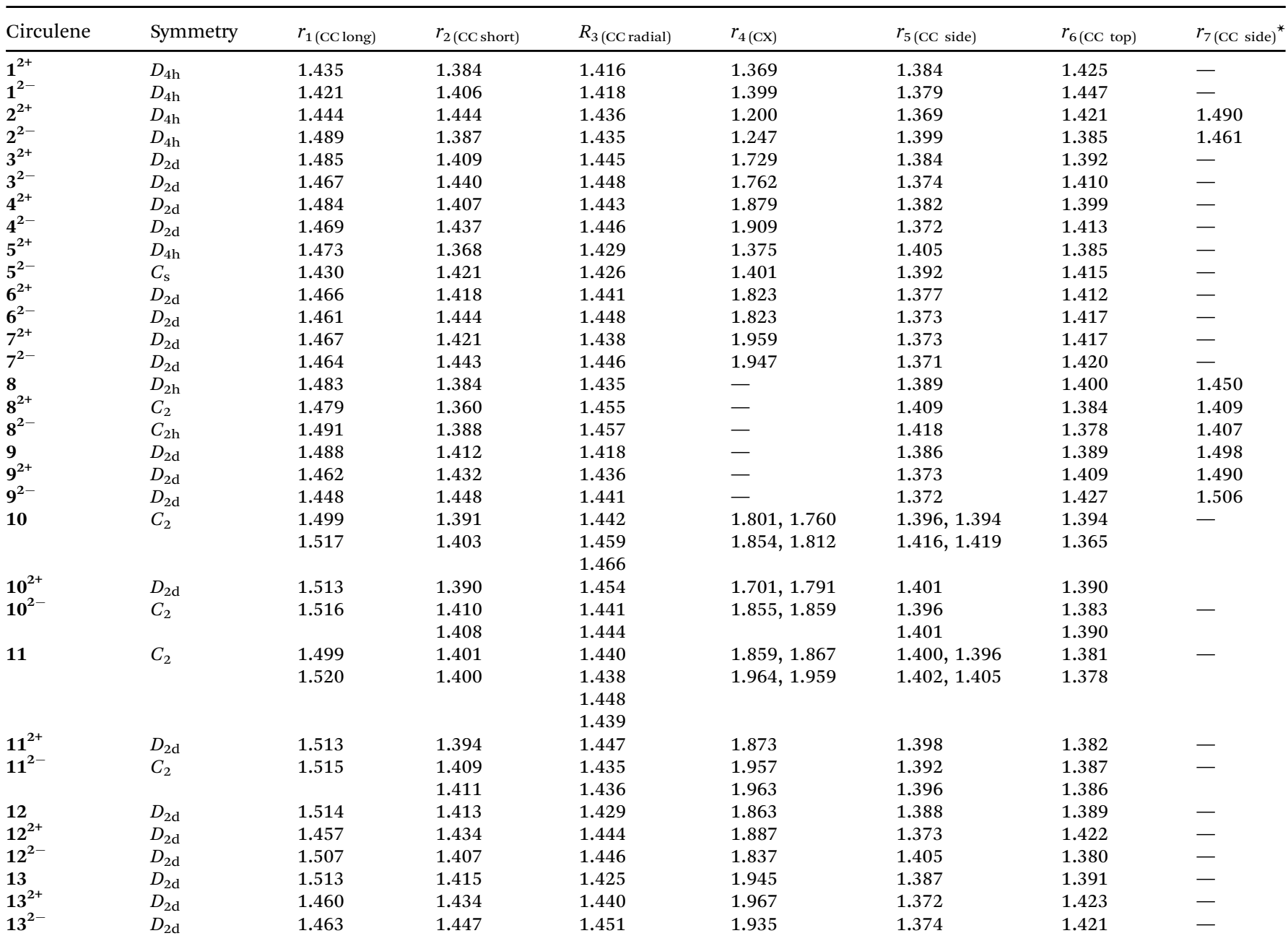

$\mathrm{X}$ denotes heteroatoms. The bond lengths of the outer side of the five-membered hydrocarbon ring in molecules $\mathbf{2}, \mathbf{8}$, and $\mathbf{9}$ are indicated with an asterisk $(*)$.

alternation in the inner cyclooctatetraene (COT) core. It should be noted that the $\mathrm{O}-, \mathrm{N}$-and $\mathrm{CO}$-containing circulenes 1, 2, and 5 possess the highest possible $D_{4 \mathrm{~h}}$ symmetry point group, while the $\mathrm{CH}$-containing compound $\mathbf{8}$ was designed with the $D_{2 \mathrm{~h}}$ symmetry in accordance with the experimental X-ray data for this species. ${ }^{74,75}$ The more symmetrical form of compound 8 (within $D_{4 \mathrm{~h}}$ symmetry) also has a minimum on the potential energy surface. In the framework of the DFT/B3LYP/6-311++G(d,p) approach both $D_{2 \mathrm{~h}}$ and $D_{4 \mathrm{~h}}$ species are degenerate by the total energy values, whereas the spin-flip (SF) DFT approach indicated that the $D_{4 \mathrm{~h}}$ form has a higher energy $\left(34.7 \mathrm{~kJ} \mathrm{~mol}^{-1}\right.$ at the SF-TD-BHHLYP/6-311G(d,p) level of approximation) than the $D_{2 \mathrm{~h}}$ model. ${ }^{74}$ Moreover, Tobe et al. found that the $D_{2 \mathrm{~h}}$ structure possesses the almost closed-shell electronic structure (with a very small diradical admixture) while the $D_{4 \mathrm{~h}}$ structure has the tetraradical character. On this basis, Tobe et al. suggested that the lower symmetry $D_{2 \mathrm{~h}}$ structure may equilibrate by valence tautomerization via the $D_{4 \mathrm{~h}}$ isomer as a transition state. ${ }^{74,75}$
The other [8]circulenes (except 9) possess nonplanar saddleshaped structures due to the sectorial excess of the macrocycle in accordance with the Wynberg-Dopper sectorial model. ${ }^{76}$ The Wynberg-Dopper sectorial model is described in detail in paragraph II.1 of ref. 40. The pure hydrocarbon compound 9 has a planar tetraphenylene skeleton except for the outer nonplanar $\mathrm{CH}_{2}$ moieties, whose hydrogens break the ideal flat structure.

The doubly charged [8]circulenes retain the molecular shape of the neutral molecules except the imidogen-containing compound 5, whose $\mathrm{N}-\mathrm{H}$ moieties deviate out-of-plane for the dianion. The doubly charged tetra-hetero[8]circulenes 3, 4, 6, and 7 are very nonplanar due to the increase in the $\mathrm{C}-\mathrm{X}$ distances as compared with the same bond lengths of the neutral molecules. The dicationic circulene $\mathbf{2}^{\mathbf{2 +}}$ and dianionic hydrocarbontype [8]circulene $\mathbf{9}^{\mathbf{2}}$ lack bond-length alternation in the inner eight-membered ring, whose $\mathrm{C}-\mathrm{C}$ bond lengths of $1.444 \AA$ and $1.448 \AA$ are practically equal suggesting that the aromatic nature of the COT core is similar to that of octathia[8]circulene and its dianion. ${ }^{52}$ 
The geometry optimizations at the DFT level yielded nonplanar molecular structures for the novel hetero[8]circulenes 10-13 (Fig. 1). The molecular structures belong to the $C_{2}$ point group for circulenes 10 and 11 and to $D_{2 \mathrm{~d}}$ for $\mathbf{1 2}$ and 13. The reason for the low symmetry of the neutral circulenes $\mathbf{1 0}$ and $\mathbf{1 1}$ and for their dianions is the two $\mathrm{sp}^{3}$-hybridized silicon and germanium atoms. Similar distortions of the molecular structure upon reduction have previously been reported for tetraza[8]circulene $\mathbf{5 .}^{52}$
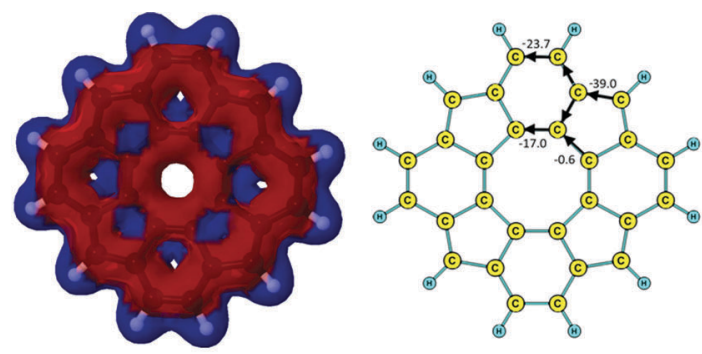

8
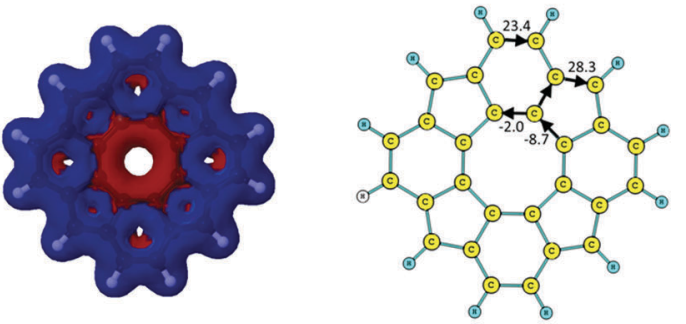

$8^{2+}$
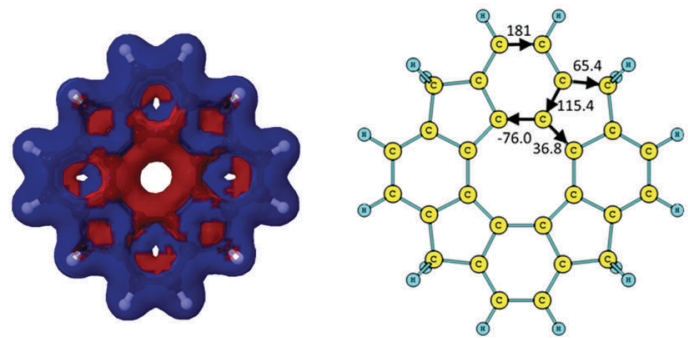

$9^{2+}$
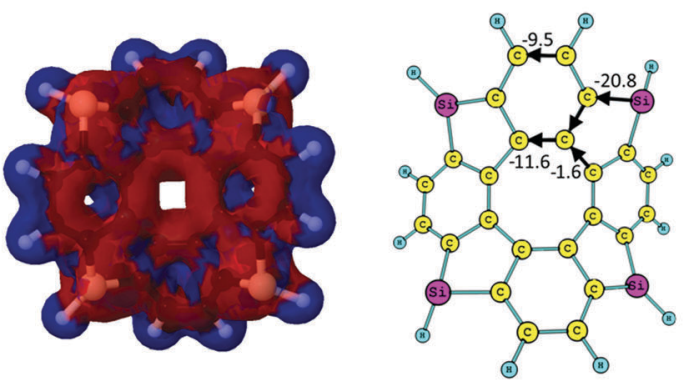

10

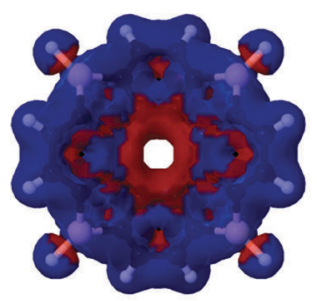

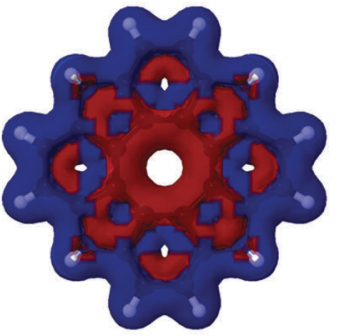

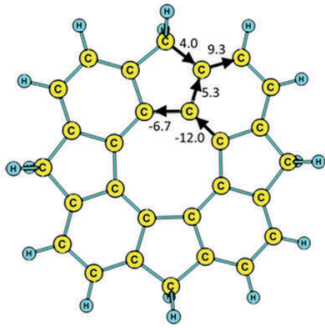

9
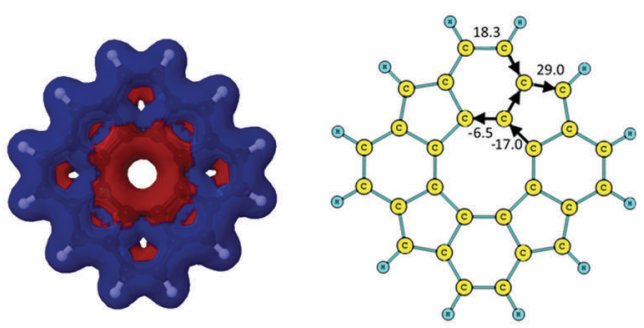

$8^{2-}$
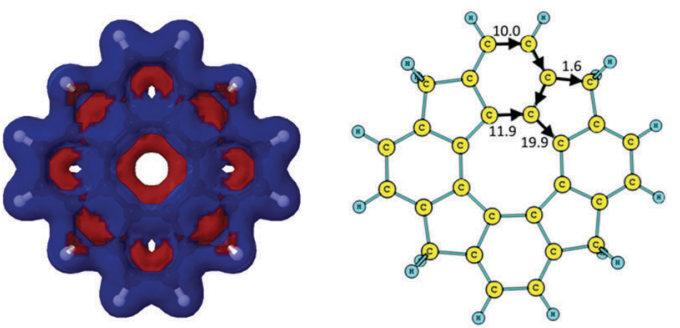

$9^{2-}$
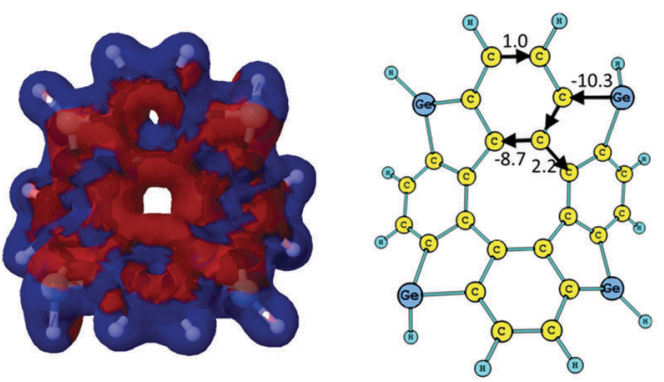

11

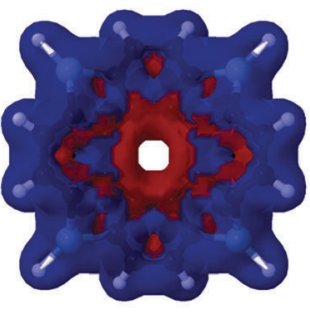

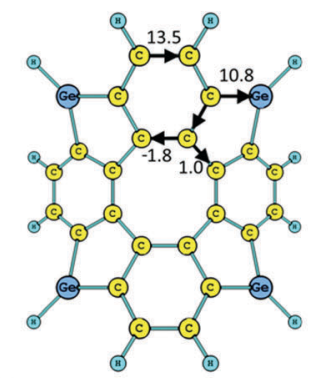

$11^{2+}$

$10^{2+}$

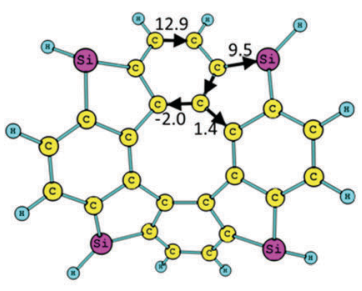



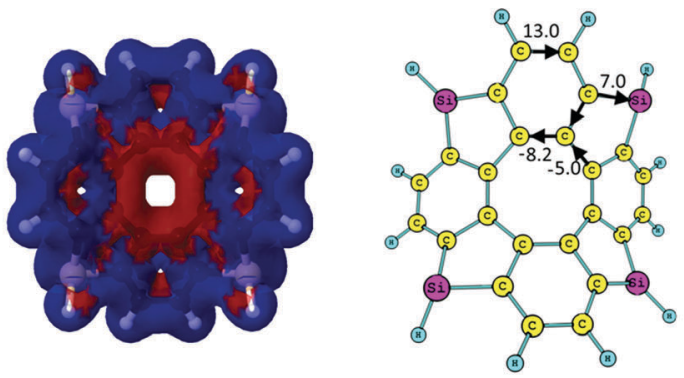

$10^{2-}$

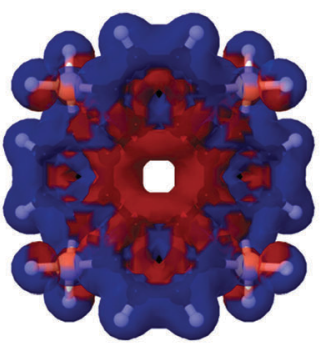

12
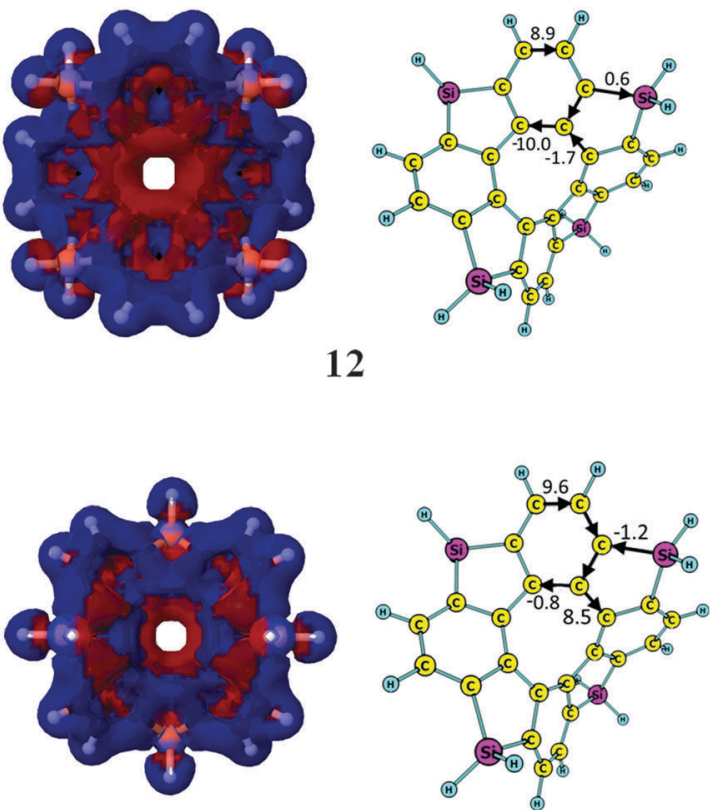

$12^{2+}$
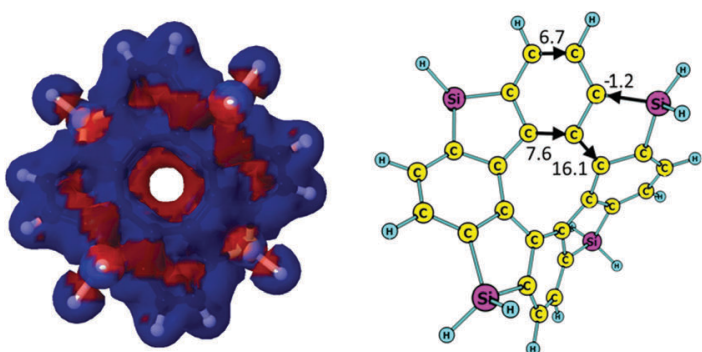

$12^{2-}$
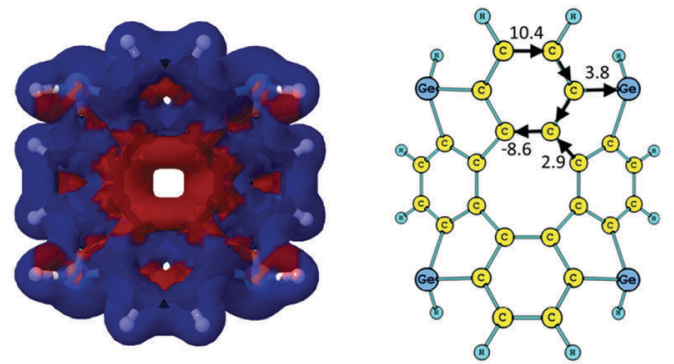

$11^{2-}$
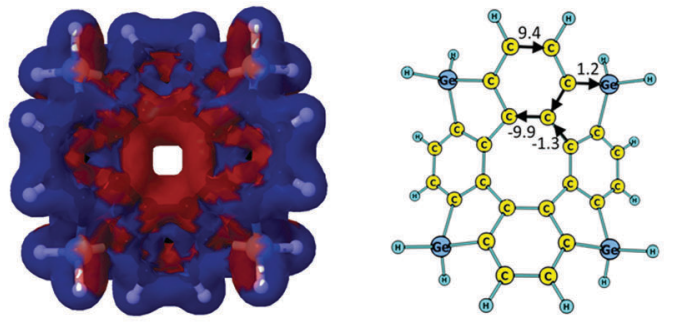

13
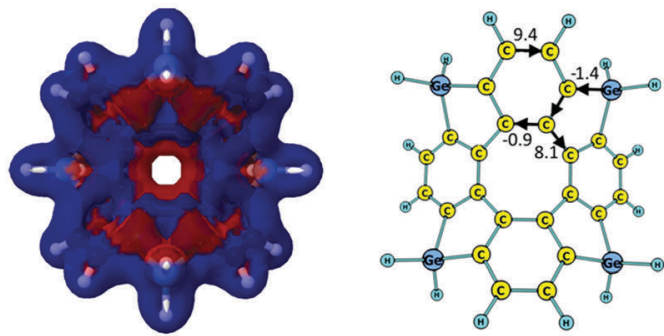

$13^{2+}$
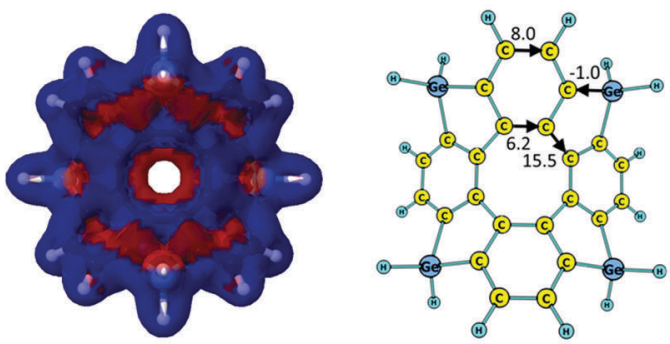

$13^{2-}$

Fig. 2 The signed modulus of the magnetically induced current densities, current strengths and current pathways for the neutral and doubly charged [8]circulenes 8-13. Paratropic current densities are shown in red and the diatropic ones in blue.

The doubly oxidized circulene dications $\mathbf{1 0}^{2+}$ and $\mathbf{1 1}^{2+}$ have high symmetry, belonging to the $D_{2 \mathrm{~d}}$ point group.

The novel [8]circulenes 10-13 have a strong bond-length alternation of the $\mathrm{C}-\mathrm{C}$ bonds in the inner COT core with variations of $0.098-0.120 \AA$ in the bond lengths, which can be compared with $0.136 \AA$ for the strongly antiaromatic free COT that also possesses $D_{2 \mathrm{~d}}$ symmetry. ${ }^{40}$ The bond lengths are given in Table 1. The bond-length alternation of the COT bonds in the inner COT core of dianionic and dicationic molecules does not exceed $0.026 \AA$, except for $\mathbf{1 2}^{2-}$, whose bond-length alternation is $0.1 \AA$. The small bond-length alternation indicates that the doubly charged molecules are more aromatic than the neutral ones. However, it is well known that equal bond lengths cannot be used as the only criterion for aromaticity, because some molecules with almost equal bond lengths are not aromatic, as discussed in ref. 65. Other criteria characterizing the aromaticity such as chemical reactivity and energetic criteria also have some limitations, whereas magnetic properties such as ${ }^{1} \mathrm{H}$ NMR chemical shifts, magnetic susceptibility exaltation, and NICS and GIMIC indices are perhaps more 
reliable than the classical criteria. They are therefore the most often used means for characterizing aromatic and antiaromatic compounds. In the next section, we discuss aromatic characters obtained using GIMIC, NICS and ${ }^{1} \mathrm{H}$ NMR calculations.

\subsection{GIMIC studies of the neutral [8]circulenes 8-13}

The signed modulus plots of the calculated magnetically induced current densities, current pathways and current strengths for the neutral [8]circulenes 8-13 are shown in Fig. 2. Current density data are given for the neutral and the corresponding charged molecules. The aromatic character of the neutral [8]circulenes 8 and 9 has been previously discussed in ref. 52 and 53. The calculated current strengths circling around the macrocycle of the neutral and doubly charged tetraphenylenes 1-13 are summarized in Table 2, which also reports how the net diatropic (aromatic) and paratropic (antiaromatic) ring currents of the studied molecules depend on the molecular charge.

In Table 2, one sees that most of the neutral [8]circulenes are practically nonaromatic, since they do not sustain any strong net ring currents around the macroring. The net ring currents vanish for $1-7$, and 9 , because the diatropic ring current in the rim and the paratropic contribution to the ring current in the hub are almost equal. In 6, 7 and 9, the benzoic rings also sustain local ring currents. The [8]circulenes with $\mathrm{CH}, \mathrm{SiH}$ and $\mathrm{GeH}$ moieties $(\mathbf{8}, \mathbf{1 0}$ and 11) are antiaromatic sustaining net paratropic (i.e., negative) ring currents, whose strength decreases with increasing atomic number. The same trend is also obtained for the corresponding $\mathrm{sp}^{3}$-hybridized $\mathrm{CH}_{2}-\mathrm{SiH}_{2^{-}}$and $\mathrm{GeH}_{2}$ containing compounds (9, 12 and 13). However, they sustain very weak net ring currents of -2.7 to $-0.5 \mathrm{nA} \mathrm{T}^{-1}$, implying that they are globally almost nonaromatic. In neutral 12 and 13, the four benzoic rings are locally aromatic, whereas very weak currents pass between the aromatic benzoic rings via the fivemembered rings (Fig. 2).

\subsection{GIMIC studies of the doubly charged [8]circulene anions}

The aromatic nature of the doubly charged circulenes 1-13 differs completely from that of the neutral ones. The current densities, current pathways and strengths are given in Fig. 2 and 3. The ring-current strengths in Table 2 show that the dianionic species

Table 2 The total ring current strength (in $n \mathrm{~A} \mathrm{~T}^{-1}$ ) and the balance between the diatropic (d) and paratropic (p) currents in the rim-and hub-subsystems for the neutrally and doubly charged tetraphenylenes 1-13

\begin{tabular}{|c|c|c|c|c|c|c|}
\hline Species & \multicolumn{3}{|l|}{ Current } & $\begin{array}{l}\text { Total current } \\
\text { strength, nA T }\end{array}$ & Conclusion & Source \\
\hline 1 & $\mathrm{~d}$ & $\mathrm{p}$ & $\mathrm{p}>\mathrm{d}$ & -2.1 & Weakly antiaromatic & Ref. 52 \\
\hline $1^{2-}$ & $\mathrm{d}$ & $\mathrm{d}$ & $2 \mathrm{~d}$ & 22 & Aromatic & This work \\
\hline 2 & $\mathrm{~d}$ & $\mathrm{p}$ & $p>d$ & -4 & Weakly antiaromatic & Ref. 51 \\
\hline $2^{2+}$ & $\mathrm{d}$ & $\mathrm{d}$ & $2 \mathrm{~d}$ & 12 & Aromatic & This work \\
\hline $2^{2-}$ & $\mathrm{d}$ & $\mathrm{p}$ & $\mathrm{d}>\mathrm{p}$ & 7.8 & Aromatic & This work \\
\hline $3^{2-}$ & $\mathrm{d}$ & $\mathrm{d}$ & $2 d$ & 19.5 & Aromatic & This work \\
\hline 4 & $\mathrm{~d}$ & $\mathrm{p}$ & $\mathrm{d} \approx \mathrm{p}$ & -1 & Almost nonaromatic & Ref. 51 \\
\hline $4^{2+}$ & $\mathrm{p}$ & $\mathrm{d}$ & $p>d$ & -74 & Strongly antiaromatic & This work \\
\hline $4^{2-}$ & $\mathrm{d}$ & $\mathrm{d}$ & $2 \mathrm{~d}$ & 17.3 & Aromatic & This work \\
\hline 5 & $\mathrm{~d}$ & $\mathrm{p}$ & $\mathrm{d} \approx \mathrm{p}$ & -0.5 & Almost nonaromatic & Ref. 52 (ESI) \\
\hline $5^{2+}$ & $\mathrm{d}$ & $\mathrm{p}$ & $p>d$ & -3 & Weakly antiaromatic & This work \\
\hline $7^{2+}$ & $\mathrm{p}$ & $\mathrm{d}$ & $p>d$ & -8 & Antiaromatic & This work \\
\hline $7^{2-}$ & $\mathrm{d}$ & $\mathrm{d}$ & $2 d$ & 15.4 & Aromatic & This work \\
\hline 8 & $\mathrm{p}$ & $\mathrm{p}$ & $2 \mathrm{p}$ & -40 & Strongly antiaromatic & Ref. 51 \\
\hline $8^{2+}$ & $\mathrm{d}$ & $\mathrm{p}$ & $\mathrm{d}>\mathrm{p}$ & 19.6 & Aromatic & This work \\
\hline $8^{2-}$ & $\mathrm{d}$ & $\mathrm{p}$ & $\mathrm{d}>\mathrm{p}$ & 11.8 & Aromatic & This work \\
\hline 9 & $\mathrm{~d}$ & $\mathrm{p}$ & $p>d$ & -2.7 & Weakly antiaromatic & Ref. 51 \\
\hline $9^{2+}$ & $\mathrm{d}$ & $\mathrm{p}$ & $d>p$ & 105 & Strongly aromatic & This work \\
\hline $9^{2-}$ & $\mathrm{d}$ & $\mathrm{d}$ & $2 d$ & 21.9 & Aromatic & This work \\
\hline 10 & $\mathrm{p}$ & $\mathrm{p}$ & $2 \mathrm{p}$ & -22.4 & Antiaromatic & This work \\
\hline $10^{2+}$ & $\mathrm{d}$ & $\mathrm{p}$ & $\mathrm{d}>\mathrm{p}$ & 10.5 & Aromatic & This work \\
\hline $10^{2-}$ & $\mathrm{d}$ & $\mathrm{p}$ & $\mathrm{d}>\mathrm{p}$ & 4.0 & Weakly aromatic & This work \\
\hline 11 & $\mathrm{p}$ & $\mathrm{p}$ & $2 p$ & -8 & Antiaromatic & This work \\
\hline $11^{2+}$ & $\mathrm{d}$ & $\mathrm{p}$ & $\mathrm{d}>\mathrm{p}$ & 11.0 & Aromatic & This work \\
\hline
\end{tabular}


generally possess aromatic character as they sustain net diatropic ring currents. The net ring currents for the dianions are positive mainly because the ring current in the inner COT core changes direction when adding two electrons. However, the current pathways of the doubly charged anions are more complicated than that. In $\mathbf{1}^{2-}, 3^{2-}, 4^{2-}$, and $5^{2-}$, the diatropic ring current passes the benzoic ring along the rim and the hub, whereas at the five-membered ring the rim current splits into an outer and inner branch of almost equal strengths. In $2^{2-}$, a diatropic current flows along the rim passing the formal single bonds of the carbonyl group, whereas a weak paratropic current circles around the hub. In $6^{2-}, 7^{2-}, 9^{2-}, \mathbf{1 2}^{2-}$ and $13^{2-}$,
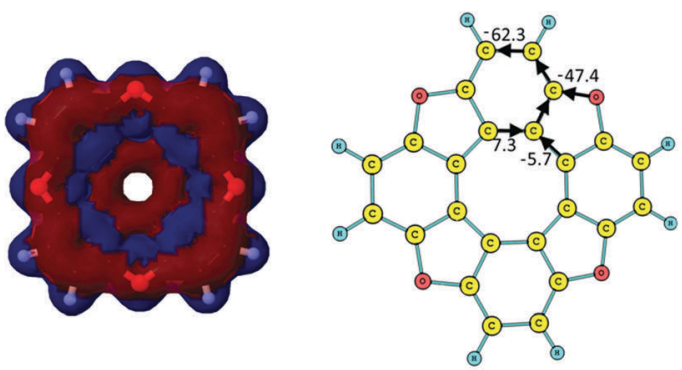

$1^{2+}$
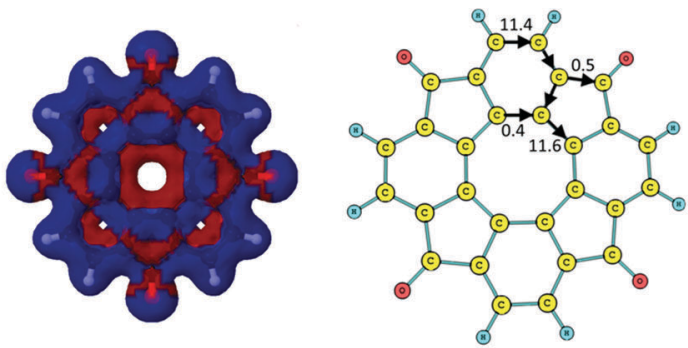

$2^{2+}$
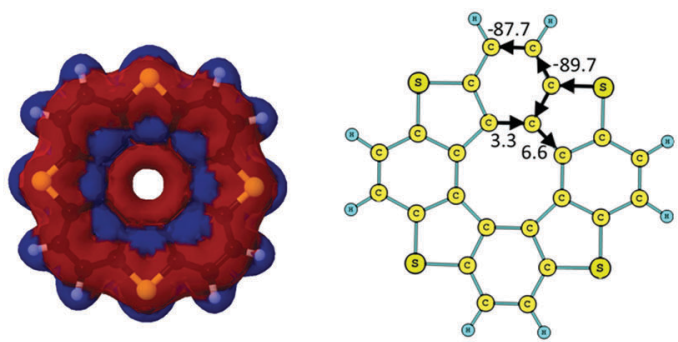

$3^{2+}$
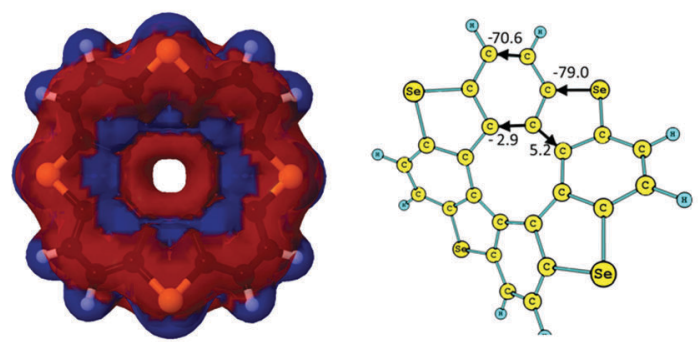

$4^{2+}$
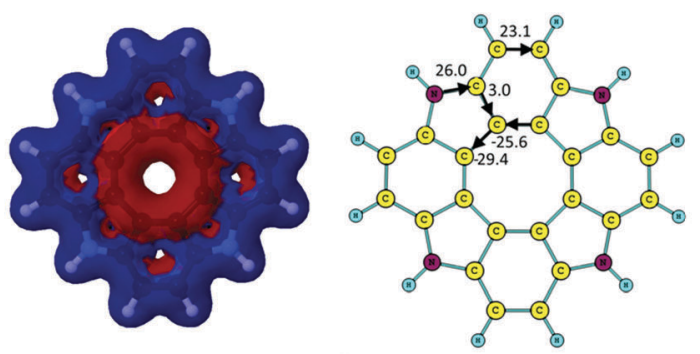

$\mathbf{5}^{++}$
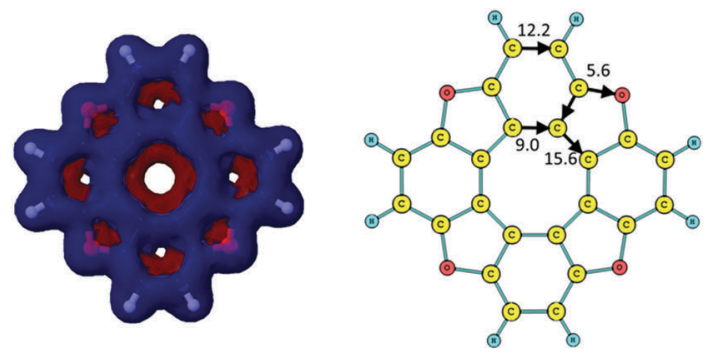

$12-$
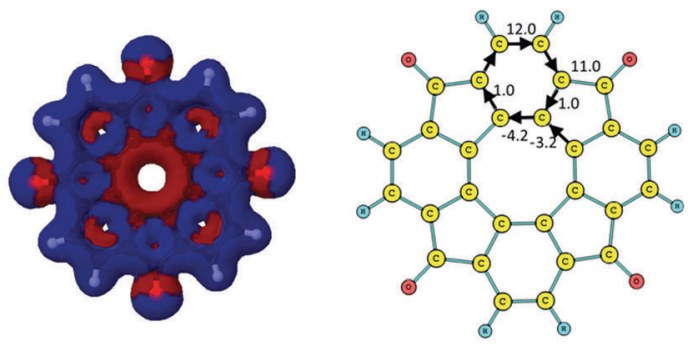

$2^{2-}$
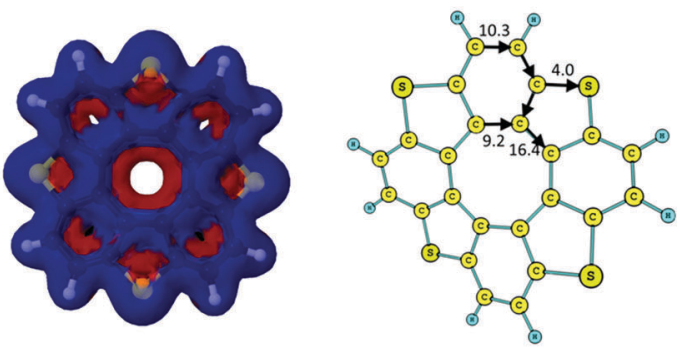

$3^{2-}$
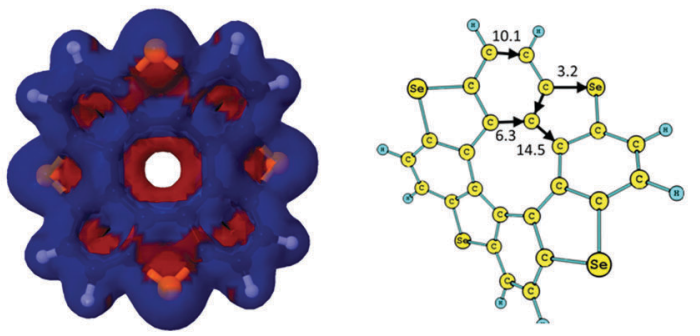

$4^{2-}$

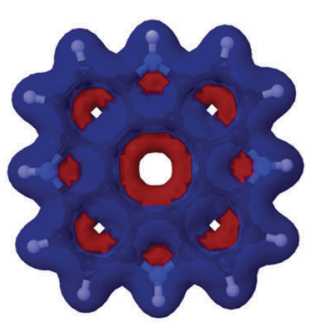

$5^{2-}$

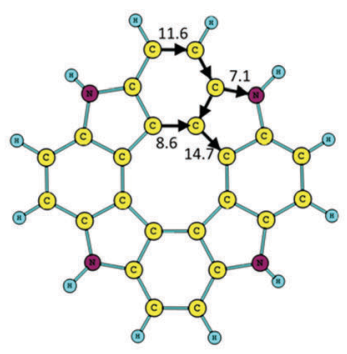



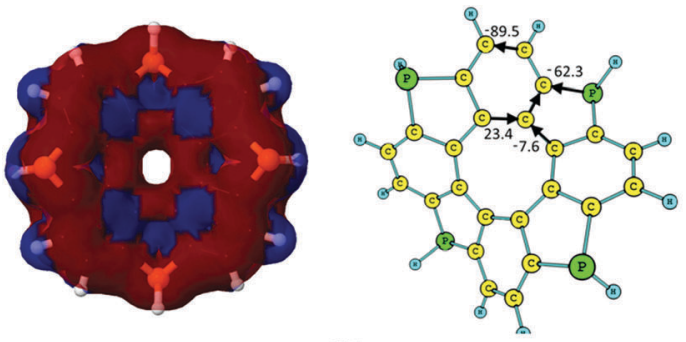

$6^{2+}$

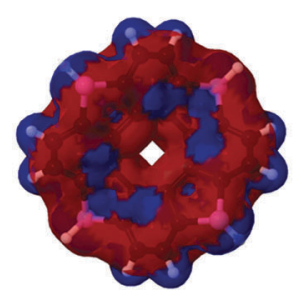

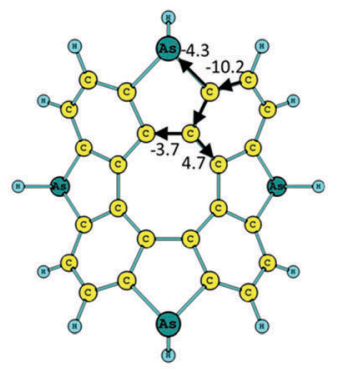

$7^{2+}$
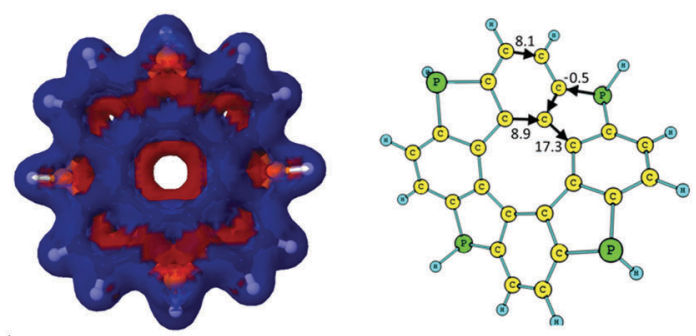

$6^{2-}$
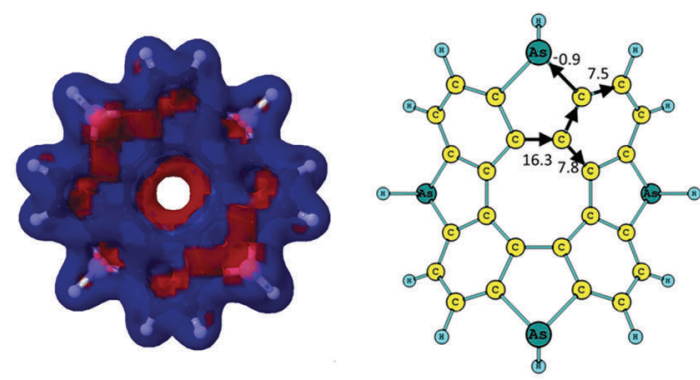

$7^{2-}$

Fig. 3 The signed modulus of the magnetically induced current densities, current strengths and current pathways for doubly charged [8]circulenes 1-7. Paratropic current densities are shown in red and the diatropic ones in blue.

the outer moieties of the five-membered rings block the ring current, whereas the hub sustains a strong diatropic ring current that splits into an outer and inner route of about equal strengths at the benzoic rings. $\mathbf{8}^{\mathbf{2 -}}$ sustains a diatropic ring current along the rim and a weaker paratropic one in the hub. In addition the five-membered rings sustain local ring currents. The net current for $\mathbf{8}^{2-}$ is diatropic (i.e. $\mathbf{8}^{2-}$ is aromatic) in good agreement with the suggestions of Tobe et al. done on the basis of NICS(1) calculations. ${ }^{75} \mathbf{1 0}^{\mathbf{2 -}}$ and $\mathbf{1 1}^{2-}$ sustain a diatropic ring current along the rim and a weak paratropic current in the hub. The benzoic rings also sustain local ring currents. For the studied molecules, the COT core gains aromatic character when adding two electrons leading to $h u b$ aromaticity or to reduced $h u b$-antiaromaticity and the ring current along the outer perimeter is in most cases diatropic, which we call rim-aromaticity. However, for some of the doubly charged anions, the outer moieties of the five-membered rings practically block the current forcing the main ring current to take the inner route. The sum of the strengths of hub- and rimcurrents yields the net ring current that determines the global aromatic character.

\subsection{GIMIC studies of the doubly charged [8]circulene cations}

The current pathways of the dications are even more irregular than the ones for the dianions. The current densities, current pathways and strengths are shown in Fig. 2 and 3. The $\mathbf{1}^{2+}$ ion sustains a strong paratropic rim current. The benzoic rings sustain a local ring current and a weak paratropic current passes on the inside of the five-membered ring leading to strong antiaromaticity. The ring current in $2^{2+}$ takes the outer route at the benzoic ring and the inner route at the fivemembered rings. Almost no current passes along the hub at the benzoic rings and along the rim of the five-membered rings. $3^{2+}$ sustains a strong paratropic rim current and a weak diatropic hub current. The five-membered rings sustain weak local paratropic ring currents. $4^{2+}$ sustains a strong paratropic rim current that splits into a weak inner branch at the benzoic rings, whereas the five-membered rings sustain local paratropic ring currents. $5^{2+}$ sustains a diatropic rim current and a paratropic hub current of about the same size leading to a practically nonaromatic molecule. The five-membered rings sustain a weak local diatropic ring current. $6^{2+}$ is strongly antiaromatic with a strong paratropic rim current. Paratropic currents also pass along the inner route of the five-membered rings and the benzoic rings sustain local paratropic ring currents. $7^{2+}$ sustains a paratropic rim current that splits at the five-membered rings into an outer and inner branch. The benzoic rings sustain weak local paratropic ring currents. $\mathbf{8}^{2+}$ is globally aromatic sustaining a strong diatropic rim current and a very weak paratropic hub current. It agrees well with the NICS(1) calculations from ref. 75 . The five-membered rings are aromatic sustaining local diatropic ring currents. $\mathbf{9}^{2+}$ is strongly aromatic sustaining a net ring current of $105 \mathrm{nA} \mathrm{T}^{-1}$. The benzoic rings are also very aromatic with a local ring current of $76 \mathrm{nA} \mathrm{T}{ }^{-1}$. At the five-membered rings the diatropic rim current is split into an outer and inner branch. Two third of the global diatropic current passes the outer $\mathrm{sp}^{3}$-hybridized $\mathrm{CH}_{2}$ moiety of the five-membered rings. $\mathbf{1 0}^{2+}$ and $\mathbf{1 1}^{2+}$ sustain global diatropic ring currents that split into a strong outer branch and a weak inner one at the fivemembered rings. The benzoic rings sustain weak local diatropic ring currents. $\mathbf{1 2}^{2+}$ and $\mathbf{1 3}^{2+}$ sustain global diatropic ring currents that take the outer route at the benzoic rings and the inner pathway at the five-membered rings. Almost no net current passes the other bonds. 


\subsection{NICS characterization}

In this section, we show that the NICS criterion cannot be employed in aromaticity studies of the [8]circulenes due to the local properties of the NICS indices. It is almost impossible to deduce a correct analysis of the complex aromatic character of the [8] circulenes by performing NICS calculations. The main differences and similarities between the NICS- and GIMIC-based results are discussed below.

The NICS values in Fig. 4 and 5 show that the dianionic [8]circulenes contain a local aromatic centre as the NICS values are negative. However, it is not apparent from the NICS calculations whether the dianionic [8]circulenes are globally aromatic or not. Only for $\mathbf{1}^{\mathbf{2 -}}-\mathbf{5}^{\mathbf{2 -}}$ and $\mathbf{8}^{\mathbf{2}-}$ the NICS indices predict that molecules are globally aromatic i.e., all the five-, six- and eightmembered rings possess local aromatic character as indicated by the negative NICS indices for each of them. NICS calculations suggest that the rest of the dianions consist of local antiaromatic five- or eight-membered cycles. However, when one accepts the idea that the paramagnetic contributions from these rings are significantly smaller than the diatropic ones, the NICS- and GIMIC-based results can be considered to agree with each other.

For the dicationic [8]circulenes, the NICS results agree with GIMIC data only for $\mathbf{8}^{2+}, \mathbf{1 0}^{2+}$, and $\mathbf{1 1}^{2+}$, which are predicted to be aromatic. The NICS indices for the other doubly oxidized species do not unambiguously provide the aromatic character as obtained in the GIMIC calculations. The NICS values have the opposite signs for the five-, six- and eight-membered rings, as shown in Fig. 4 and 5. Moreover, the analysis of the NICS indices for the dications $1^{2+}, 5^{2+}-7^{2+}$ and the neutral 9, 12, 13 species suggests that they are aromatic rather than antiaromatic, which disagrees with the GIMIC results.

In summary, we conclude that the NICS criterion is rather unreliable for obtaining the correct description of the complex aromatic nature of the neutral and doubly charged hetero[8]circulenes due to the local character of NICS indices. However, using the GIMIC approach one can explicitly calculate the current strength and current pathways providing an accurate and detailed picture of the ring current pathways rendering it possible to determine the aromatic character of molecules with complex annelated rings.
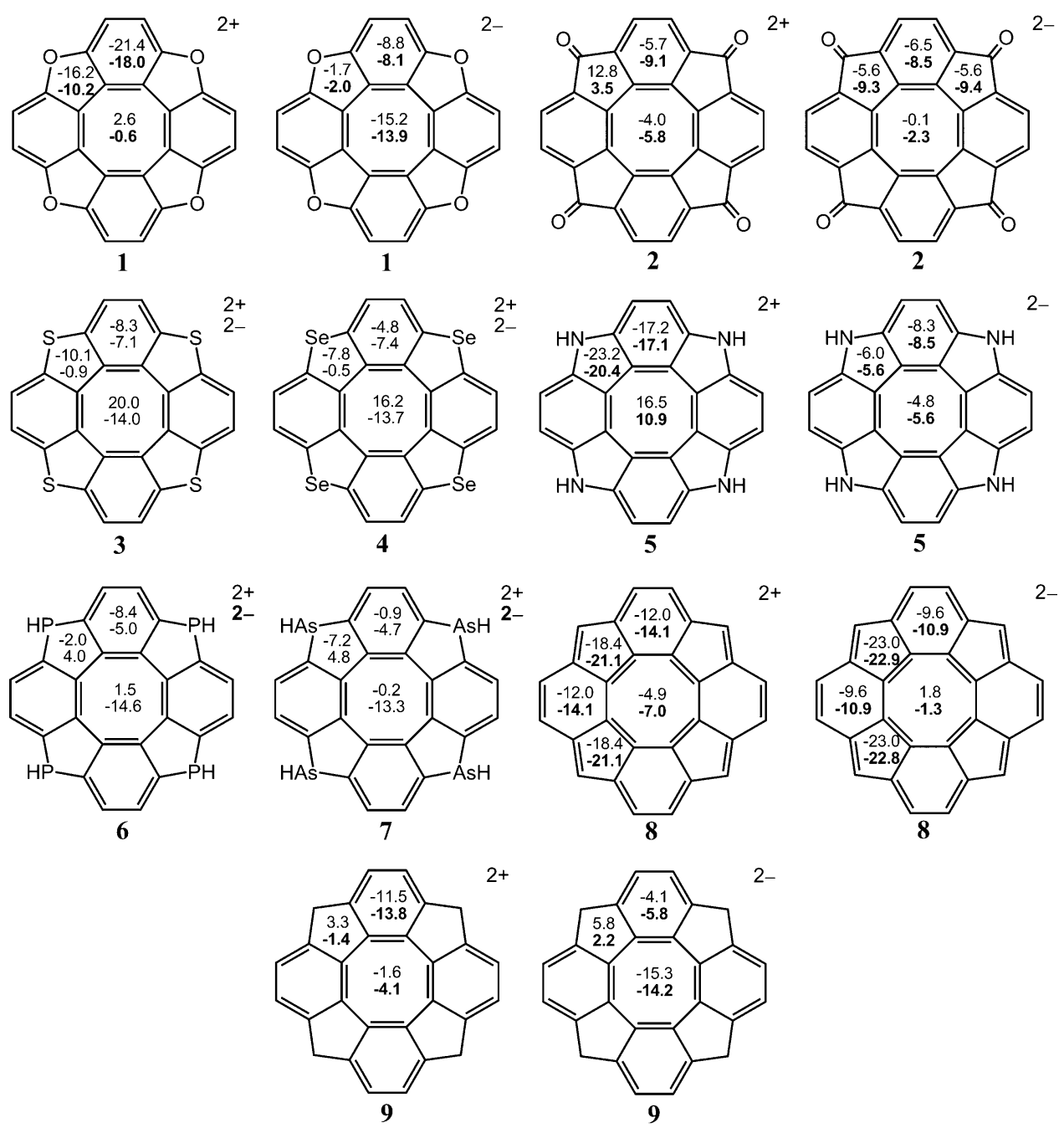

Fig. 4 The NICS(0) and NICS(1) (in bold when available) indices for the doubly charged circulenes 1-9. 

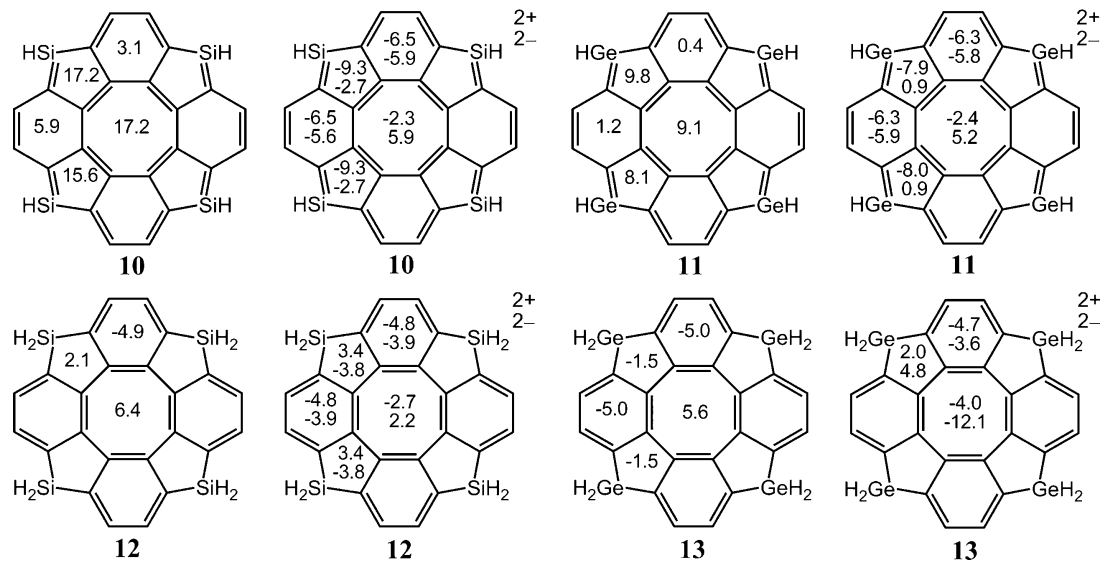

Fig. 5 The NICS(0) indices for the neutral and doubly charged [8]circulenes 10-13.

\section{6. ${ }^{1} \mathrm{H}$ NMR chemical shift characterization}

Spectroscopic measurements of proton NMR chemical shifts $\left({ }^{1} \mathrm{H}\right.$ NMR) are one of the most popular experimental methods to assess the aromaticity of polycyclic compounds. Diatropic (aromatic) ring currents deshield the protons at the outer edge of the molecule leading downfield shift of the ${ }^{1} \mathrm{H}$ NMR signal relative to the tetramethylsilane (TMS) reference. The general aromatic chemical shift region for the protons directly connected to the aromatic framework varies in the wide range of 6.5-9 ppm and the chemical shift strongly depends on the type and position of heteroatom in the carbon skeleton.

Comparisons of the calculated isotropic magnetic shielding constants with the ${ }^{1} \mathrm{H}$ NMR shielding constant for TMS calculated at the same level of theory yield the calculated values for the ${ }^{1} \mathrm{H}$ NMR chemical shifts in Table 3 . The calculated ${ }^{1} \mathrm{H}$ NMR chemical shifts of the hydrogens of the benzoic rings of the neutral [8]circulenes fall in the aromatic range. The exceptions are compounds 8, 10 and 11, which possess the rim-antiaromaticity implying that the corresponding NMR signals are upfield shifted, which is in good agreement with the experimental data for compound 8. The ${ }^{1} \mathrm{H}$ NMR chemical shifts describe correctly the rim aromaticity of the neutral species as obtained in the
GIMIC calculation. For the dianionic [8]circulenes, the hydrogens of the benzoic rings are characterized by aromatic ${ }^{1} \mathrm{H}$ NMR chemical shift values. The same also holds for the benzoic protons of the $\mathrm{NH}, \mathrm{PH}, \mathrm{AsH}, \mathrm{CH}$ (compound 8), $\mathrm{SiH}$ and $\mathrm{GeH}$ containing compounds. These results are in good agreement with the GIMIC and NICS results. For the dicationic species the aromatic character deduced from the ${ }^{1} \mathrm{H}$ NMR chemical shifts does not agree with the ones obtained in the GIMIC calculations. The chemical shifts in Table 3 show that the hydrogens of the benzoic rings and the ones at the heteroatoms are significantly deshielded, which might indicate that the molecule sustains a strong diatropic ring current along the perimeter, which is in contradiction to the GIMIC results. We conclude that the ${ }^{1} \mathrm{H}$ NMR chemical shift criterion as well as NICS criterion for aromaticity is not able to correctly describe the aromatic character of the hetero[8]circulene dications. For the neutral and dianionic species, the ${ }^{1} \mathrm{H}$ NMR chemical shift indices provide a more reliable description of the aromaticity. A further limitation of the ${ }^{1} \mathrm{H}$ NMR chemical shift criterion is that the inner COT core of the [8]circulenes does not contain any directly fused protons, which means that the criterion cannot be applied for assessing the hub aromaticity.

Table 3 Calculated and measured ${ }^{1} \mathrm{H}$ NMR chemical shifts for the studied circulenes

\begin{tabular}{llll}
\hline & \multicolumn{2}{l}{ Chemical shift range $(\delta), \mathrm{ppm}$} & \\
\cline { 2 - 4 } Circulene & $\mathbf{2}^{+}$ & $\mathbf{0}$ & $\mathbf{2}^{-}$ \\
\hline $\mathbf{1}$ & $10.89(8 \mathrm{CH})$ & $7.80 / 7.68^{a}(8 \mathrm{CH})$ & $6.58(8 \mathrm{CH})$ \\
$\mathbf{2}$ & $10.18(8 \mathrm{CH})$ & $7.72(8 \mathrm{CH})$ & $6.63 / 8.47(8 \mathrm{CH})$ \\
$\mathbf{3}$ & $9.80(8 \mathrm{CH})$ & $8.23(8 \mathrm{CH})$ & $7.05(8 \mathrm{CH})$ \\
$\mathbf{4}$ & $6.86(8 \mathrm{CH})$ & $7.92(8 \mathrm{CH})$ & $6.18(8 \mathrm{CH}), 5.16(4 \mathrm{NH})$ \\
$\mathbf{5}$ & $10.12(8 \mathrm{CH}), 12.58(4 \mathrm{NH})$ & $7.68(8 \mathrm{CH}), 7.95(4 \mathrm{NH})$ & $7.07(8 \mathrm{CH}), 6.74(4 \mathrm{PH})$ \\
$\mathbf{6}$ & $9.43(8 \mathrm{CH}), 7.73(4 \mathrm{PH})$ & $7.63(8 \mathrm{CH}), 5.82(4 \mathrm{PH})$ & $6.89(8 \mathrm{CH}), 6.26(4 \mathrm{AsH})$ \\
$\mathbf{7}$ & $7.26(8 \mathrm{CH}), 9.08(4 \mathrm{AsH})$ & $7.32(8 \mathrm{CH}), 5.50(4 \mathrm{AsH})$ & $8.78(8 \mathrm{CH}), 9.42(4 \mathrm{CH})$ \\
$\mathbf{8}$ & $12.03(8 \mathrm{CH}), 13.08(4 \mathrm{CH})$ & $1.24(8 \mathrm{CH}), 0.70(4 \mathrm{CH}) / 2.86^{b}$ & $6.60(8 \mathrm{CH}), 4.06\left(4 \mathrm{CH}{ }_{2}\right)$ \\
$\mathbf{9}$ & $10.04(8 \mathrm{CH}), 5.67(4 \mathrm{CH})$ & $7.43(8 \mathrm{CH}), 3.92(4 \mathrm{CH} 2)$ & $7.18-7.19(4 \mathrm{SiH}), 7.76-7.96(8 \mathrm{CH})$ \\
$\mathbf{1 0}$ & $9.68(8 \mathrm{CH}), 9.21(4 \mathrm{SiH})$ & $5.25-5.68(4 \mathrm{SiH}), 4.91-5.50(8 \mathrm{H})$ & $7.33(4 \mathrm{GeH}), 7.98-7.33(8 \mathrm{CH})$ \\
$\mathbf{1 1}$ & $9.44(8 \mathrm{CH}), 9.98(4 \mathrm{GeH})$ & $6.12-7.62(4 \mathrm{GeH}), 5.99-7.22(8 \mathrm{H})$ & $\left.6.62-6.58(4 \mathrm{SiH})_{2}\right), 7.58-7.52(8 \mathrm{CH})$ \\
$\mathbf{1 2}$ & $5.92-6.17\left(4 \mathrm{SiH}_{2}\right), 8.99(8 \mathrm{CH})$ & $5.20\left(4 \mathrm{SiH} \mathrm{H}_{2}\right), 7.92(8 \mathrm{CH})$ & $\left.5.33-5.35(4 \mathrm{GeH})_{2}\right), 6.96-6.89(8 \mathrm{CH})$
\end{tabular}

${ }^{a}$ Experimental data from Ref. 56. ${ }^{b}$ Experimental data from Ref. 75. 


\section{Conclusions}

In the present work, we have presented the structural characterisation and aromaticity descriptions of the doubly charged [8]circulenes 1-9 and the novel neutral, dicationic and dianionic circulenes 10-13. We have used the three most popular magnetic criteria of aromaticity, namely the gauge including magnetically induced current (GIMIC) method, calculated nucleus-independent chemical shift (NICS) values and ${ }^{1} \mathrm{H}$ NMR chemical shifts to solve the posed problem. We have found that the GIMIC-based results for the studies on neutral and doubly charged [8]circulenes are much more informative than the local NICS indices and ${ }^{1} \mathrm{H}$ NMR chemical shifts, because the GIMIC approach provides very detailed information about the current pathways, which is not feasible when using the local NICS and ${ }^{1} \mathrm{H}$ NMR chemical shifts indices.

We found that most of the studied [8]circulenes (except compounds 8, 10 and 11) have a bifacial aromatic/antiaromatic character in the neutral form; the inner octatetraene core (also called $h u b$ ) sustains a paratropic (antiaromatic) ring current, whereas the ring current of the outer macrocycle (the rim) is diatropic (aromatic). The aromatic character changes drastically when charging the [8]circulenes; the dianionic [8]circulenes and OC-, $\mathrm{CH}-, \mathrm{CH}_{2}-$, $\mathrm{SiH}-, \mathrm{GeH}-, \mathrm{SiH}_{2}-$, and $\mathrm{GeH}_{2}$-containing dicationic species sustain net diatropic ring currents i.e., they are aromatic, whereas O-, S-, Se-, NH-, PH- and AsH-containing dicationic compounds are strongly antiaromatic, because they are dominated by the paratropic ring currents. The present computational study of the magnetically induced current densities suggests that the experimentally observed high stability of the synthesized [8]circulenes 1-5 and $\mathbf{9}$ is due to their rimaromaticity, even though they are nonaromatic. The rim aromaticity favours substitution reactions of the [8]circulenes 1-5 and 9, analogously to benzoic compounds. The carbon atoms of the hub are protected against substitution reactions, because they are $\mathrm{sp}^{2}$ hybridized without any available hydrogen atom to replace. Addition reactions to the $h u b$ carbons would lead to a transformation from $\mathrm{sp}^{2}$ to $\mathrm{sp}^{3}$ hybridization that significantly affects most of the $\mathrm{C}-\mathrm{C}$ bonds of the [8]circulene, which is expected to lead to a very high reaction barrier. Compound $\mathbf{8}$ is antiaromatic suggesting that it is unstable, which is in good agreement with experimental data. ${ }^{75}$ The same most likely also holds for the rest of the studied [8]circulenes, which have not yet been synthesized. The GIMIC approach opens up new possibilities for studies of the electronic structure of complex polycyclic aromatic compounds like [8]circulenes.

\section{Acknowledgements}

The calculations were performed with computational resources provided by the Swedish National Infrastructure for Computing (SNIC) at the Parallel Computer Center (PDC) through the project "Multiphysics Modeling of Molecular Materials", SNIC 020/11-23 and by CSC - the Finnish IT Center for Science. We are grateful for support from the Academy of Finland projects 275845 and 266227 . This research was also supported by the
Ministry of Education and Science of Ukraine (project number 0115U000637). B. F. Minaev acknowledges the fellowship of Chinese Academy of Science under the CAS President's International Initiative for Visiting Scientists.

\section{References}

1 T. M. Krygowski and M. K. Cyrański, Chem. Rev., 2001, 101, 1385.

2 M. K. Cyrański, Chem. Rev., 2005, 105, 3773.

3 A. R. Katritzky, P. Barczynski, G. Musumarra, D. Pisano and M. Szafran, J. Am. Chem. Soc., 1989, 111, 7.

4 M. K. Cyrański, T. M. Krygowski, A. R. Katritzky and P. v. R. Schleyer, J. Org. Chem., 2002, 67, 1333.

5 K. Jug and A. M. Koster, J. Phys. Org. Chem., 1991, 4, 163.

6 (a) R. Gershoni-Poranne and A. Stanger, Chem. Soc. Rev., 2015, 44, 6597; (b) C. Foroutan-Nejad, S. Shahbazian and P. Rashidi-Ranjbar, Phys. Chem. Chem. Phys., 2010, 12, 12630.

7 (a) S. C. A. H. Pierrefixe and F. M. Bickelhaupt, Chem. - Eur. J., 2007, 13, 6321; (b) S. C. A. H. Pierrefixe and F. M. Bickelhaupt, Chem. - Eur. J., 2007, 13, 8371; (c) S. C. A. H. Pierrefixe and F. M. Bickelhaupt, J. Phys. Chem. A, 2008, 112, 12816.

8 P. v. R. Schleyer, C. Maerker, H. C. Dransfeld, H. Jiao and N. J. R. van Eikema Hommes, J. Am. Chem. Soc., 1996, 118, 6317.

9 Z. Badri, S. Pathak, H. Fliegl, P. Rashidi-Ranjbar, R. Bast, R. Marek, C. Foroutan-Nejad and K. Ruud, J. Chem. Theory Comput., 2013, 9, 4789.

10 C. Foroutan-Nejad, Theor. Chem. Acc., 2015, 134, 8.

11 J. Jusélius and D. Sundholm, Phys. Chem. Chem. Phys., 1999, $1,3429$.

12 E. Steiner, P. Fowler, A. Soncini and L. W. Jenneskens, Faraday Discuss., 2007, 135, 309.

13 J. Jusélius and D. Sundholm, J. Org. Chem., 2000, 65, 5233.

14 Y.-C. Lin, J. Jusélius and D. Sundholm, J. Chem. Phys., 2005, 122, 214308.

15 P. W. Fowler, R. W. A. Havenith and E. Steiner, Chem. Phys. Lett., 2002, 359, 530.

16 J. Jusélius, S. Michal and D. Sundholm, J. Phys. Chem. A, 2001, 105, 9939.

17 Y.-C. Lin, D. Sundholm, J. Jusélius, L.-F. Cui, H.-J. Zhai and L.-S. Wang, J. Phys. Chem. A, 2006, 110, 4244.

18 C. A. Tsipis, Coord. Chem. Rev., 2005, 249, 2740.

19 Y.-C. Lin and D. Sundholm, J. Chem. Theory Comput., 2006, 2, 761.

20 H. Fliegl, S. Taubert, O. Lehtonen and D. Sundholm, Phys. Chem. Chem. Phys., 2011, 13, 20500.

21 J. Jusélius, D. Sundholm and J. Gauss, J. Chem. Phys., 2004, 121, 3952.

22 H. Fliegl, D. Sundholm, S. Taubert, J. Jusélius and W. Klopper, J. Phys. Chem. A, 2009, 113, 8668.

23 H. Fliegl, N. Özcan, R. Mera-Adasme, F. Pichierri, J. Jusélius and D. Sundholm, Mol. Phys., 2013, 111, 1364. 
24 R. R. Valiev, H. Fliegl and D. Sundholm, J. Phys. Chem. A, 2013, 117, 9062.

25 R. R. Valiev, H. Fliegl and D. Sundholm, J. Phys. Chem. A, 2015, 119, 1201.

26 R. R. Valiev, H. Fliegl and D. Sundholm, Phys. Chem. Chem. Phys., 2015, 17, 14215.

27 M. P. Johansson, J. Jusélius and D. Sundholm, Angew. Chem., Int. Ed., 2005, 44, 1843.

28 S. Taubert, D. Sundholm and F. Pichierri, J. Org. Chem., 2010, 75, 5867.

29 S. Taubert, J. Jusélius, D. Sundholm, W. Klopper and H. Fliegl, J. Phys. Chem. A, 2008, 112, 13584.

30 V. T. T. Huong, T. B. Tai and M. T. Nguyen, Phys. Chem. Chem. Phys., 2012, 14, 14832.

31 V. T. T. Huong, H. T. Nguyen, T. B. Tai and M. T. Nguyen, J. Phys. Chem. C, 2013, 117, 10175.

32 G. V. Baryshnikov, N. N. Karaush and B. F. Minaev, Chem. Heterocycl. Compd., 2014, 50, 349.

33 W. Wei, F.-Q. Bai, B.-H. Xia, H.-B. Chen and H.-X. Zhang, Chem. Res. Chin. Univ., 2013, 29, 962.

34 A. Kerim, New J. Chem., 2014, 38, 3783.

35 K. Y. Chernichenko, V. V. Sumerin, R. V. Shpanchenko, E. S. Balenkova and V. G. Nenajdenko, Angew. Chem., Int. Ed., 2006, 45, 7367.

36 B. F. Minaev, G. V. Baryshnikov and V. A. Minaeva, Comput. Theor. Chem., 2011, 972, 68.

37 N. N. Karaush, B. F. Minaev, G. V. Baryshnikov and V. A. Minaeva, Opt. Spectrosc., 2014, 116, 33.

38 T. B. Tai, V. T. T. Huong and M. T. Nguyen, Chem. Commun., 2013, 49, 11548-11550.

39 N. N. Karaush, R. R. Valiev, G. V. Baryshnikov, B. F. Minaev and H. Ågren, Chem. Phys., 2015, 459, 65.

40 G. V. Baryshnikov, B. F. Minaev and V. A. Minaeva, Russ. Chem. Rev., 2015, 84, 455.

41 T. B. Tai, H. T. T. Vu and M. T. Nguyen, RSC Adv., 2015, $5,24167$.

42 X. Xiong, C.-L. Deng, B. F. Minaev, G. V. Baryshnikov, X.-S. Peng and H. N. C. Wong, Chem. - Asian J., 2014, 9, 1.

43 T. N. Gribanova, N. S. Zefirov and V. I. Minkin, Pure Appl. Chem., 2010, 82, 1011.

44 G. V. Baryshnikov, V. A. Minaeva, B. F. Minaev, N. N. Karaush, X.-D. Xiong, M.-D. Li, D. L. Phillips and H. N. C. Wong, Spectrochim. Acta, Part A, 2015, 151, 247.

45 G. V. Baryshnikov, B. F. Minaev, N. N. Karaush and V. A. Minaeva, Phys. Chem. Chem. Phys., 2014, 16, 6555.

46 G. V. Baryshnikov, B. F. Minaev, N. N. Karaush and V. A. Minaeva, RSC Adv., 2014, 4, 25843.

47 N. N. Karaush, G. V. Baryshnikov and B. F. Minaev, RSC Adv., 2015, 5, 24299.

48 N. N. Karaush, G. V. Baryshnikov, B. A. Minaeva and B. F. Minaev, New J. Chem., 2015, 39, 7815.

49 J. Yu, Q. Sun, Y. Kawazoe and P. Jena, Nanoscale, 2014, 6, 14962. 50 S. Radenković, I. Gutman and P. Bultinck, J. Phys. Chem. A, 2012, 116, 9421.

51 G. V. Baryshnikov, B. F. Minaev, M. Pittelkow, C. B. Nielsen and R. Salcedo, J. Mol. Model., 2013, 19, 847.
52 G. V. Baryshnikov, R. R. Valiev, N. N. Karaush and B. F. Minaev, Phys. Chem. Chem. Phys., 2014, 16, 15367.

53 G. V. Baryshnikov, N. N. Karaush, R. R. Valiev and B. F. Minaev, J. Mol. Model., 2015, 21, 136.

54 C. B. Nielsen, T. Brock-Nannestad, T. K. Reenberg, P. Hammershoj, J. B. Christensen, J. W. Stouwdam and M. Pittelkow, Chem. - Eur. J., 2010, 16, 13030.

55 J. Eskildsen, T. Reenberg and J. B. Christensen, Eur. J. Org. Chem., 2000, 1637.

56 T. Brock-Nannestad, C. B. Nielsen, M. Schau-Magnussen, P. Hammershoj, T. K. Reenberg, A. B. Petersen, D. Trpcevski and M. Pittelkow, Eur. J. Org. Chem., 2011, 6320.

57 A. Dadvand, F. Cicoira, K. Y. Chernichenko, E. S. Balenkova, R. M. Osuna, F. Rosei, V. G. Nenajdenko and D. F. Perepichka, Chem. Commun., 2008, 5354.

58 H. Erdtman and H.-E. Högberg, Tetrahedron Lett., 1970, 11, 3389.

59 A. D. Becke, J. Chem. Phys., 1993, 98, 5648.

60 C. Lee, W. Yang and R. G. Parr, Phys. Rev. B: Condens. Matter Mater. Phys., 1988, 37, 785.

61 R. Krishnan, J. S. Binkley, R. Seeger and J. A. Pople, J. Chem. Phys., 1980, 72, 650.

62 M. J. Frisch, G. W. Trucks, H. B. Schlegel, G. E. Scuseria, M. A. Robb, J. R. Cheeseman, G. Scalmani, V. Barone, B. Mennucci, G. A. Petersson, H. Nakatsuji, M. Caricato, X. Li, H. P. Hratchian, A. F. Izmaylov, J. Bloino, G. Zheng, J. L. Sonnenberg, M. Hada, M. Ehara, K. Toyota, R. Fukuda, J. Hasegawa, M. Ishida, T. Nakajima, Y. Honda, O. Kitao, H. Nakai, T. Vreven, J. A. Montgomery Jr, J. E. Peralta, F. Ogliaro, M. Bearpark, J. J. Heyd, E. Brothers, K. N. Kudin, V. N. Staroverov, R. Kobayashi, J. Normand, K. Raghavachari, A. Rendell, J. C. Burant, S. S. Iyengar, J. Tomasi, M. Cossi, N. Rega, J. M. Millam, M. Klene, J. E. Knox, J. B. Cross, V. Bakken, C. Adamo, J. Jaramillo, R. Gomperts, R. E. Stratmann, O. Yazyev, A. J. Austin, R. Cammi, C. Pomelli, J. W. Ochterski, R. L. Martin, K. Morokuma, V. G. Zakrzewski, G. A. Voth, P. Salvador, J. J. Dannenberg, S. Dapprich, A. D. Daniels, Ö. Farkas, J. B. Foresman, J. V. Ortiz, J. Cioslowski and D. J. Fox, Gaussian 09, revision C.02, Gaussian, Inc, Wallingford, CT, 2009.

63 T. K. Zywietz, H. Jiao, P. V. R. Schleyer and A. De Meijere, J. Org. Chem., 1998, 63, 3417.

64 P. R. Schleyer, Chem. Rev., 2001, 101, 1115.

65 Z. Chen, C. S. Wannere, C. Corminboeuf, R. Puchta and P. R. Schleyer, Chem. Rev., 2005, 105, 3842.

66 A. Stanger, J. Org. Chem., 2006, 71, 883.

67 K. Wolinski, J. F. Hilton and P. Pulay, J. Am. Chem. Soc., 1990, 112, 8251.

68 J. R. Cheeseman, G. W. Trucks, T. A. Keith and J. M. Frisch, J. Chem. Phys., 1996, 104, 5497.

69 G. Monaco, P. W. Fowler, M. Lillington and R. Zanasi, Angew. Chem., Int. Ed., 2007, 46, 1889.

70 R. R. Valiev, H. Fliegl and D. Sundholm, Phys. Chem. Chem. Phys., 2014, 16, 11010. 
71 R. R. Valiev and V. N. Cherepanov, Int. J. Quantum Chem., 2013, 113, 2563.

72 F. Furche, R. Ahlrichs, C. Hättig, W. Klopper, M. Sierka and F. Weigend, Comput. Mol. Biosci., 2014, 4, 91.

73 JMOL: an open-source Java viewer for chemical structures in 3D., http://www.jmol.org.
74 S. Nobusue, H. Miyoshi, A. Shimizu, I. Hisaki, K. Fukuda, M. Nakano and Y. Tobe, Angew. Chem., Int. Ed., 2015, 54, 2090.

75 H. Miyoshi, S. Nobusue, A. Shimizu and Y. Tobe, Chem. Soc. Rev., 2015, 44, 6560.

76 J. H. Dopper and H. Wynberg, J. Org. Chem., 1975, 40, 1957. 